\title{
FOLLOW-UP OF A CARDIOVASCULAR PREVENTION CAMPAIGN
}

\author{
Dirk Devroey, Ellie Senesael, Tania Moerenhout, Erwin Van De Vijver, Jan Vandevoorde \\ Department of Family Medicine, University of Brussels (VUB), Brussels, Belgium
}

\begin{abstract}
SUMMARY
The aim of this study was to evaluate the cardiovascular risk (CVR) factors and morbidity in a sample of the population that received a brief intervention on cardiovascular prevention seven years ago. All family physicians who participated in the Cardiovascular Prevention Campaign in five Belgian towns in 2002-2003 received a follow-up questionnaire for each participating patient. The questionnaire included questions about new cardiovascular diagnoses, parameters of the latest physical examination and blood tests. Analyses were based on the 318 questionnaires that included essential information such as the date of the latest contact and the new diagnosis or mortality. The proportion of patients with a low CVR decreased from $75 \%$ in 2002-2003 to 40\% in 2010. Participants showed a significant increase of the abdominal circumference, triglycerides and fasting glycaemia. Only LDL-cholesterol levels decreased significantly $(p=0.002)$. Four percent of the patients died, more male $(7 \%)$ than female $(2 \%)(p=0.03)$. One in ten patients presented with a cardiovascular event. Most of the changes are probably attributable to age. It is clear that the long-term effect of a brief intervention only followed by usual care is not sufficient to attain optimal level of cardiovascular prevention.
\end{abstract}

Key words: cardiovascular risk, hypertension, cholesterol, diabetes, mortality

Address for correspondence: D. Devroey, Department of Family Medicine, Vrije University of Brussels, Laarbeeklaan 103, B-1090 Brussels, Belgium. E-mail: dirk.devroey@vub.ac.be

\section{INTRODUCTION}

In Europe, cardiovascular disease accounts for $49 \%$ of mortality and for $30 \%$ of all premature death before the age of 65 years (1). It is well known that among patients at high cardiovascular risk (CVR), not all individual risk factors are well controlled (2). Despite their huge impact on morbidity and mortality, the individual risk factors are not always diagnosed and if yes, they are often not adequatly treated (3-5). Even in secondary prevention treatment targets concerning lifestyle, risk factors and therapy are not reached, despite the fact that this group has an increased risk of a new cardiovascular event (6).

Cardiovascular prevention should not only focus on a limited number of CVR factors but should target all risk factors because of their cumulative influence on the cardiovascular system $(4,7$, 8). Family physicians are in a unique position to motivate their patients to change their daily lifestyle, and to initiate a follow up medical treatment resulting in a better management of cardiovascular disease (9).

In 2002, the local authorities of five Belgian towns (Hoeilaart, Oud-Heverlee, Huldenberg, Merchtem and Overijse) invited all inhabitants aged between 45 and 65 years for a cardiovascular check-up by their family physician. The participants received lifestyle advice or treatment according to their estimated CVR (10). At that time, interventions for lipoproteins, glycaemia and smoking were implemented more frequently in patients with mild and increased CVR compared to those with low CVR. Isolated CVR factors often remained untreated among participants with low CVR.
A Danish study with 200 participants aged between 30 and 50 years showed that the CVR decreased among participants who had had a health check-up compared to those who had not (11). Five years after the intervention, the proportion of participants with an increased CVR was half as high in the intervention group compared to the control group. The impact of the intervention was higher in the group with high CVR.

A study in The Netherlands (Nijmegen), initiated in 1977 among participants aged between 20 and 50 years, showed that 18 years after a cardiovascular intervention no changes in CVR were observed (12). At the same time participants with a low CVR still belonged to the group with low CVR. From the above studies we can state that there is only little or discordant information about the long term effects of brief interventions in cardiovascular prevention.

The aim of our study was to evaluate the CVR and outcome in terms of morbidity in a sample of the population that received a brief intervention on cardiovascular prevention in the towns of Huldenberg and Oud-Heverlee seven years ago and in the towns of Hoeilaart, Merchtem and Overijse eight years ago.

\section{MATERIALS AND METHODS}

\section{Design and Study Population}

All family physicians $(\mathrm{N}=51)$ who participated in the 2002-2003 study in the towns of Hoeilaart, Merchtem,Overijse, Oud-Heverlee and Huldenberg were invited to participate in the 
follow-up study. In the initial study, all patients aged between 45 and 65 years were invited by their local authority to visit their family physician for a cardiovascular check-up. Participating patients completed a questionnaire about their CVR factors and underwent a physical examination by their family physician. A blood sample was taken if there was no blood test available from the past 12 months (10).

In February and March 2010 the family physicians received a follow-up questionnaire for every patient who had taken part in 2002 or 2003 study. These patients could be identified by their unique identification number alloted during the 2002-2003 registration, or by their birthday, gender and medical history, if this number was no longer available at the surgery. The questionnaire included questions concerning new medical events since the initial registration and results from the latest medical examination, including systolic blood pressure (SBP), diastolic blood pressure (DBP), heart-rate, body weight, length and abdominal circumference. The latest measurements for total cholesterol (TC), low-density lipoprotein-cholesterol (LDL-C), high-density lipoprotein-cholesterol (HDL-C), triglycerides (TG), and fasting glycaemia were recorded, as well as the actual treatment including medications and diets prescribed by the family physicians and the dieticians. For diabetics, glycosylated haemoglobin A (HbA1c) was also recorded.

\section{Ethical Approval}

The initial study protocol was approved by the ethics review board of the Flemish Institute for General Practice (Vlaams Huisartsen Instituut; VHI). The study protocol of the follow-up study was approved by the ethical committee of the University Hospital of Brussels.

\section{Laboratory Testing}

Serum TC, TG and HDL-C were measured enzymatically. LDL-C levels were calculated with the Friedewald formula, except when measured TG levels were above $300 \mathrm{mg} / \mathrm{dL}$ (13). In that case LDL-C levels were also measured enzymatically. All measurements were performed by local laboratories. These laboratories are regularly subjected to internal as well as external quality controls, according to the Belgian rules for clinical biology, thus guaranteeing the quality of their measurements. Since one of the aims of this study was to evaluate how GPs deal and make use of results they receive from their local laboratories in real life conditions and knowing that the absolute values of the measured parameters were of minor importance for our study, it was in our opinion not relevant to perform all tests in one central laboratory or to standardize the results.

\section{Target Levels}

According to the recommendations of the European Fourth Joint Task Force the upper limits for screening and target goals for hypertension were defined as SBP at $140 \mathrm{~mm} \mathrm{Hg}$ and/or $\mathrm{DBP}$ at $90 \mathrm{~mm} \mathrm{Hg}(2,14)$. For diabetics, patients with high cardiovascular risk and patients with a history of stroke or coronary heart disease the target blood pressure was defined at $130 / 80 \mathrm{~mm} \mathrm{Hg}(2,7)$.
The target for TC is $190 \mathrm{mg} / \mathrm{dL}$ or less for all patients in primary prevention without diabetes or a family history of cardiovascular disease, and $175 \mathrm{mg} / \mathrm{dL}$ or less for diabetics and patients with a history of cardiovascular disease $(1,2)$. The target level for LDL$\mathrm{C}$ is $115 \mathrm{mg} / \mathrm{dL}$ or less. For high risk patients, diabetic patients and patients with a history of cardiovascular disease, the LDL-C target is determined at $100 \mathrm{mg} / \mathrm{dL}$. Statins are advised if after three months of life style changes these target levels are not reached (2).

For TG and HDL-C no specific target levels are defined. However, there is consensus about the fact that there is an increased risk for cardiovascular diseases if HDL-C is lower than $40 \mathrm{mg}$ / $\mathrm{dL}$ among men and lower than $45 \mathrm{mg} / \mathrm{dL}$ among women (2). For TG a similar risk exists for levels of $150 \mathrm{mg} / \mathrm{dL}$ or more. Type 2 diabetes is defined as fasting plasma glucose of $126 \mathrm{mg} / \mathrm{dL}$ or more, on more than one occasion $(2,15)$. Impaired fasting glucose (IFG) is defined as fasting plasma glucose between 100 and 126 $\mathrm{mg} / \mathrm{dL}$. According to the recommendations of the European Fourth Joint Task Force, the goals for adequate glucose control in Type 1 (insulin-dependent) diabetes are: fasting blood glucose between 91 and $120 \mathrm{mg} / \mathrm{dL}$ with postprandial glycaemia between 136 and $160 \mathrm{mg} / \mathrm{dL}, \mathrm{HbA} 1 \mathrm{c}$ between 6.2 and $7.5 \%$, and avoidance of serious hypoglycaemias (16). In the present study adequate glucose control is defined as HbA1c below 7.0\%.

Participants are categorized as overweight when the body mass index (BMI) is between 25.0 and $29.9 \mathrm{~kg} / \mathrm{m}^{2}$, and are considered obese if their BMI is $30.0 \mathrm{~kg} / \mathrm{m}^{2}$ or more $(2,17)$.

Target levels for abdominal circumference (AC) are $102 \mathrm{~cm}$ for men and $88 \mathrm{~cm}$ for women (2).

Risk assessment for determining 10-year risk for a fatal cardiovascular disease is carried out according to the Systemic Coronary Risk Evaluation (SCORE) (6). The CVR is defined as being high, medium or low if the calculated 10 -year risk is over $10 \%$, between 5 and $10 \%$, or below $5 \%$, respectively. The SCORE evaluates CVR according to age, gender, smoking status, SBP and the ratio of TC over HDL-C $(7,18)$. However, CVR could be underestimated in case of familiar premature cardiovascular disease (men younger than 55 years and women younger than 65 years), diabetes, obesity, sedentary lifestyle, low HDL-C and high TG, and finally in asymptomatic patients with preclinical atherosclerosis (for example with a decreased ankle-arm index) (17).

\section{Statistical Analysis}

SPSS-PC 18 software was used for analysis and statistical processing. A chi-square test was performed to detect differences between groups.

Treatments by GPs are known to show high intra-practice correlations. Patients attending a particular practice are much more similar than patients from different practices when it comes to information, drug treatment and lifestyle advice. To account for clustering of patients within some practices, multilevel logistic regression analysis was used on the patient-level data. These were performed using the MLwiN 2.16 software package (19). To assess the potential of confounding by differences in patient populations among practices, all rates were adjusted for the effects of particular practice as well as for patient age and sex. Because these adjusted rates were almost identical to the unadjusted rates, only the latter are presented in this paper. 
Multivariate analyses were performed with backward stepwise logistic regression analysis to look at the association between mortality or occurrence of a cardiovascular event and the presence of CVR factors.

The three CHD risk groups characterized on the basis of the SCORE risk assessment are likely to differ substantially in their age and gender distribution. Therefore, any comparison between these groups is likely to be confounded by age and sex. For that reason the figures for the CHD risk groups were standardized for age and sex according to the Belgian population aged between 45 and 64 years in 2009.

\section{RESULTS}

\section{Participants}

Of the 51 participating family physicians in the original study, 17 agreed to participate in the follow-up study. In total, 384 questionnaires were returned. Analyses were performed on the 318 questionnaires that were sufficiently completed to provide at least information about the date of the latest visit, recent cardiovascular events and mortality.

The participants consisted of $40 \%(\mathrm{n}=128)$ men and $60 \%$ $(n=190)$ women. They had a mean age of 63.9 years $(S D=7.1)$. The mean age of men was 64.1 years $(\mathrm{SD}=7.1)$ and of women 63.5 years $(\mathrm{SD}=7.1)$.

\section{Evolution of Cardiovascular Parameters}

Table 1 shows that in 2010 , for the total population, a significant increase was observed in the AC, TG and fasting glycaemia, as well as a significant decrease in LDL-C. In the female population only the $\mathrm{AC}$ and fasting glycaemia showed a significant increase. In the male population SBP, weight, $\mathrm{AC}$ and fasting glycaemia increased significantly, whereas TC and LDL-C were significantly lower.

\section{Evolution of Target Level Attainment}

No significant changes in the attainment of target levels for blood pressure and lipids were observed, except for TG where a significant decrease was seen in the proportion of the total and the male population that attained the $150 \mathrm{mg} / \mathrm{dL}$ target (Table 2). In this context it is important to know that $42 \%$ of participants with increased TC were not treated, neither were $47 \%$ of the participants with increased LDL-C, $20 \%$ of those with increased TG, $39 \%$ of those with decreased HDL-C and $33 \%$ of participants with hypertension.

In 2010, significantly fewer participants met the target levels for blood sugar $(<100 \mathrm{mg} / \mathrm{dL})$ (especially men) and for BMI $(<25$ $\mathrm{kg} / \mathrm{m}^{2}$ or $<30 \mathrm{~kg} / \mathrm{m}^{2}$ ) (especially women). Seven percent of men and $4 \%$ of women had diabetes.

The proportion of overweight participants increased from $54 \%$ to $63 \%(p=0.019)$. The proportion of obese participants also increased from $14 \%$ to $23 \%(\mathrm{p}=0.003)$.

\section{Evolution of Cardiovascular Risk}

Table 3 shows that the proportion of patients in primary prevention attributed to the high CVR class had more than doubled from $11 \%$ in $2002-2003$ to $23 \%$ in 2010 ( $p<0.001)$. The proportion of patients with a mild CVR had almost multiplied by four from $6 \%$ to $22 \%(\mathrm{p}<0.001)$. Consequently, the proportion of patients with a low CVR had decreased from $75 \%$ to $40 \%(\mathrm{p}<0.001)$.

In $2003,8 \%$ of the patients were in secondary prevention, this proportion increased to $15 \%$ in 2010 . The shifts in CVR were also significant in both sexes.

\section{Morbidity and Mortality}

Table 4 shows the occurrence of several new diseases among men and women. Hypertension (16\%), dyslipidaemia (10\%) and diabetes $(5.5 \%)$ were the most common new diagnoses in both sexes. Significantly more coronary artery procedures were recorded among men than in women $(p=0.04)$. New cases of

Table 1. Evolution of the cardiovascular parameters between 2002-2003 and 2010

\begin{tabular}{|c|c|c|c|c|c|c|c|c|c|}
\hline & \multicolumn{3}{|c|}{ Total population $(\mathrm{N}=318)$} & \multicolumn{3}{|c|}{ Female population $(\mathrm{N}=190)$} & \multicolumn{3}{|c|}{ Male population $(\mathrm{N}=128)$} \\
\hline & 2002-2003 & 2010 & \multirow{2}{*}{$p$} & $2002-2003$ & 2010 & \multirow{2}{*}{$\mathrm{p}$} & 2002-2003 & 2010 & \multirow{2}{*}{$p$} \\
\hline & Mean (SD) & Mean (SD) & & Mean (SD) & Mean (SD) & & Mean (SD) & Mean (SD) & \\
\hline $\mathrm{SBP}(\mathrm{mm} \mathrm{Hg})$ & $130.4(14.6)$ & $132.5(12.8)$ & NS & $130.7(15.2)$ & $131.7(12.9)$ & NS & $130.0(13.7)$ & $133.5(12.6)$ & 0.04 \\
\hline $\mathrm{DBP}(\mathrm{mm} \mathrm{Hg})$ & $80.4(10.9)$ & $79.9(6.9)$ & NS & $80.0(10.4)$ & $79.8(6.9)$ & NS & $80.7(11.6)$ & $80.2(7.2)$ & NS \\
\hline Weight (kg) & $72.7(13.2)$ & $73.4(14.6)$ & NS & $70.8(15.1)$ & $68.6(9.9)$ & NS & $75.4(14.1)$ & $82.2(18.1)$ & 0.02 \\
\hline $\mathrm{BMI}\left(\mathrm{kg} / \mathrm{m}^{2}\right)$ & $26.6(16.7)$ & $26.8(4.5)$ & NS & $27.0(21.6)$ & $26.5(4.1)$ & NS & $26.1(4.3)$ & $27.2(5.1)$ & NS \\
\hline $\mathrm{AC}(\mathrm{cm})$ & $85.2(11.7)$ & $92.7(13.7)$ & $<0.001$ & $84.6(10.6)$ & $89.3(10.4)$ & 0.012 & $87.9(13.2)$ & $95.7(15.9)$ & 0.004 \\
\hline $\mathrm{TC}(\mathrm{mg} / \mathrm{dL})$ & $213.8(37.4)$ & $208.5(40.6)$ & NS & $214.9(38.3)$ & $212.3(42.8)$ & NS & $213.7(37.2)$ & $203.2(37.4)$ & 0.03 \\
\hline LDL-C (mg/dL) & $129.7(35.7)$ & $120.2(34.8)$ & 0.002 & $128.2(34.9)$ & $121.0(35.6)$ & NS & $131.0(37.3)$ & $118.1(33.5)$ & 0.006 \\
\hline $\mathrm{HDL}-\mathrm{C}(\mathrm{mg} / \mathrm{dL})$ & $62.4(17.0)$ & $64.0(20.4)$ & NS & 64.4 (16.8) & $68.4(21.6)$ & NS & $59.6(16.7)$ & $56.5(16.2)$ & NS \\
\hline TG (mg/dL) & $110.7(58.1)$ & $121.1(76.8)$ & 0.039 & $108.8(54.7)$ & $112.8(67.8)$ & NS & $116.7(68.8)$ & $135.1(87.0)$ & NS \\
\hline Gluc (mg/dL) & $92.8(18.1)$ & $99.4(24.6)$ & 0.001 & $92.2(17.0)$ & $96.7(17.8)$ & 0.017 & $95.3(20.2)$ & $103.9(32.6)$ & 0.02 \\
\hline
\end{tabular}

Abbreviations: $\mathrm{SBP}=$ systolic blood pressure, $\mathrm{DBP}=$ diastolic blood pressure, $\mathrm{BMI}=$ body mass index, $\mathrm{AC}=$ abdominal circumference, $\mathrm{TC}=$ total cholesterol. $\mathrm{LDL}-\mathrm{C}=$ low-density lipoprotein cholesterol, HDL-C = high-density lipoprotein cholesterol, $\mathrm{TG}=$ triglycerides. Gluc = fasting glucose, $\mathrm{NS}=$ not significant 
Table 2. Evolution of target level attainment between 2002-2003 and 2010

\begin{tabular}{|c|c|c|c|c|c|c|c|c|c|}
\hline & \multicolumn{3}{|c|}{ Total population $(\mathrm{N}=318)$} & \multicolumn{3}{|c|}{ Female population $(\mathrm{N}=190)$} & \multicolumn{3}{|c|}{ Male population $(\mathrm{N}=128)$} \\
\hline & 2002-2003 & 2010 & \multirow{2}{*}{$\mathrm{p}$} & 2002-2003 & 2010 & \multirow{2}{*}{$\mathrm{p}$} & $2002-2003$ & 2010 & \multirow{2}{*}{$\mathrm{p}$} \\
\hline & $n(\%)$ & $n(\%)$ & & $n(\%)$ & $n(\%)$ & & $\mathrm{n}(\%)$ & $n(\%)$ & \\
\hline $\mathrm{TC}<190 \mathrm{mg} / \mathrm{dL}$ & $84(26)$ & $103(32)$ & NS & $48(25)$ & $57(30)$ & NS & $36(28)$ & $46(36)$ & NS \\
\hline LDL-C <115 mg/dL & $121(38)$ & $136(43)$ & NS & $70(37)$ & $84(44)$ & NS & $51(40)$ & $52(41)$ & NS \\
\hline $\mathrm{TG}<150 \mathrm{mg} / \mathrm{dL}$ & $251(79)$ & $228(72)$ & 0.04 & $156(82)$ & $148(78)$ & NS & $95(74)$ & $80(66)$ & 0,048 \\
\hline $\mathrm{HDL}-\mathrm{C}>40 \mathrm{mg} / \mathrm{dL}$ & $298(94)$ & $295(93)$ & NS & $184(97)$ & $184(97)$ & NS & $114(89)$ & $111(87)$ & NS \\
\hline Gluc $<126$ mg/dL & $304(96)$ & $296(93)$ & NS & $182(96)$ & $182(96)$ & NS & $122(95)$ & $114(89)$ & NS \\
\hline Gluc <100 mg/dL & $250(79)$ & $223(70)$ & 0.013 & $150(79)$ & $141(74)$ & NS & $100(78)$ & $82(64)$ & 0,014 \\
\hline $\mathrm{BP}<140 / 90 \mathrm{~mm} \mathrm{Hg}$ & $204(64)$ & $187(59)$ & NS & $122(64)$ & $118(62)$ & NS & $82(64)$ & $69(54)$ & NS \\
\hline $\mathrm{BMl}<25 \mathrm{~kg} / \mathrm{m}^{2}$ & $147(46)$ & $118(37)$ & 0.019 & $91(48)$ & $72(38)$ & 0.049 & $56(44)$ & $46(36)$ & NS \\
\hline $\mathrm{BMI}<30 \mathrm{~kg} / \mathrm{m}^{2}$ & $273(86)$ & $243(77)$ & 0.003 & $169(89)$ & $146(77)$ & 0.002 & $104(81)$ & $97(76)$ & NS \\
\hline
\end{tabular}

Abbreviations: $\mathrm{BP}=$ blood pressure, $\mathrm{BMI}=$ body mass index, TC = total cholesterol, LDL-C = low-density lipoprotein cholesterol, HDL-C = high-density lipoprotein cholesterol, $\mathrm{TG}=$ triglycerides, Gluc $=$ fasting glucose, $\mathrm{NS}=$ not significant

chronic obstructive pulmonary disease $(\mathrm{COPD})(\mathrm{p}=0.006)$ and gout $(\mathrm{p}=0.03)$ were recorded significantly more often among men than women.

A cardiovascular event was defined as: myocardial infarction, stroke, transient ischemic attack, coronary artery procedure, angina pectoris or peripheral vascular disease. Table 5 shows that most $\mathrm{CV}$ events were non-fatal, and occurred significantly more in men $(17 \%)$ than in women $(5 \%)(\mathrm{p}<0.001)$.

Seven years after the inclusion $4 \%$ of the patients had died with more men $(7 \%)$ than women $(2 \%)(p=0.03)$ being affected. Only two patients had died because of a cardiovascular event, both men.

Using a multivariate logistic regression analysis with mortality as the dependent variable we could not detect a relationship between mortality and cardiovascular risk factors. Neither could we detect a relationship between the occurrence of a cardiovascular event and the presence of the different CVR factors, using a second multivariate logistic regression analysis with the occurrence of a cardiovascular event as dependent variable.

\section{DISCUSSION}

Only $25 \%$ of the original 1,283 participants were included in the follow-up study, consisting of subjects from all five participat- ing towns. This low response rate was partly due to the fact that only 17 of the 51 family physicians participating in the original study also participated in our follow up. However, despite this low response rate, we are quite confident that our results are representative for the initial study population, because the low response was not due to a lack of interest among participants, but to low participation of family physicians. Because of an insufficient number of participants in secondary prevention, it was not appropriate trying to detect changes in treatment and outcome for these patients.

\section{Cardiovascular Risk Factors}

The prevalence of CVR factors is increasing worldwide. It is estimated that the three most important causes of mortality will be hypertension, smoking and high cholesterol (8).

The cholesterol levels from different studies are difficult to compare because of the heterogeneity of study populations. A French study, for example, reported higher values for total cholesterol (268 mg/dL) and LDL-C (179 mg/dL), although the inclusion criteria were quite similar to ours (20). On the other hand, a British study, showed quite similar results for TC (203 $\mathrm{mg} / \mathrm{dL})$ and LDL-C (120mg/dL) as in our study (21).

Compared to 2003-2004, the abdominal circumference, TG and glycaemia increased significantly in 2010. Only LDL-C decreased during the follow-up.

Table 3. Evolution of CVR between 2002-2003 and 2010

\begin{tabular}{|c|c|c|c|c|c|}
\hline & \multicolumn{2}{|c|}{$2002-2003(\mathrm{~N}=318)$} & \multicolumn{2}{|c|}{$2010(\mathrm{~N}=318)$} & \multirow{2}{*}{$\mathrm{p}$-value } \\
\hline & $n$ & $\%$ & $\mathrm{n}$ & $\%$ & \\
\hline \multicolumn{6}{|l|}{ Primary prevention } \\
\hline Low CVR & 237 & 74.5 & 128 & 40.3 & $<0.001$ \\
\hline Mild CVR & 19 & 6.0 & 70 & 22.0 & $<0.001$ \\
\hline High CVR & 36 & 11.3 & 72 & 22.6 & $<0.001$ \\
\hline Secondary prevention & 26 & 8.2 & 48 & 15.1 & 0.007 \\
\hline
\end{tabular}

Abbreviations: $\mathrm{CVR}=$ Cardiovascular risk 
Table 4. Occurence of new events: comparison between men and women

\begin{tabular}{|c|c|c|c|c|c|c|c|}
\hline & \multicolumn{2}{|c|}{ Total $(\mathrm{N}=318)$} & \multicolumn{2}{|c|}{ Men (N=128) } & \multicolumn{2}{|c|}{ Women (N=190) } & \multirow{2}{*}{$\mathrm{p}$-value } \\
\hline & $\mathrm{n}$ & $\%$ & $\mathrm{n}$ & $\%$ & $\mathrm{n}$ & $\%$ & \\
\hline Myocardial infarction & 7 & 2.2 & 5 & 3.9 & 2 & 1.1 & 0.01 \\
\hline Periferal vascular disease & 4 & 1.3 & 2 & 1.6 & 2 & 1.1 & NS \\
\hline Heart failure & 2 & 0.6 & 1 & 0.8 & 1 & 0.5 & NS \\
\hline Hypertension & 48 & 15.1 & 19 & 14.8 & 29 & 15.3 & NS \\
\hline Dyslipidemia & 33 & 10.4 & 13 & 10.2 & 20 & 10.5 & NS \\
\hline Coronary artery procedures & 8 & 2.5 & 6 & 4.7 & 2 & 1.1 & 0.04 \\
\hline Gout & 3 & 0.9 & 3 & 2.3 & 0 & 0.0 & 0.03 \\
\hline Angina & 11 & 3.5 & 7 & 5.5 & 4 & 2.1 & NS \\
\hline Stroke & 1 & 0.3 & 1 & 0.8 & 0 & 0.0 & NS \\
\hline TIA & 1 & 0.3 & 1 & 0.8 & 0 & 0.0 & NS \\
\hline Astma & 2 & 0.6 & 2 & 1.6 & 0 & 0.0 & NS \\
\hline COPD & 5 & 1.6 & 5 & 3.9 & 0 & 0.0 & 0.006 \\
\hline Diabetes & 17 & 5.3 & 9 & 7.0 & 8 & 4.2 & NS \\
\hline Total & 142 & 44.7 & 74 & 57.8 & 68 & 35.8 & $<0.001$ \\
\hline
\end{tabular}

Table 5. Cumulative new events: comparison between men and women

\begin{tabular}{|c|c|c|c|c|c|c|c|}
\hline & \multicolumn{2}{|c|}{ Total $(\mathrm{N}=318)$} & \multicolumn{2}{|c|}{ Men $(\mathrm{N}=128)$} & \multicolumn{2}{|c|}{ Women $(\mathrm{N}=190)$} & \multirow{2}{*}{ p-value } \\
\hline & $\mathrm{n}$ & $\%$ & $\mathrm{n}$ & $\%$ & $\mathrm{n}$ & $\%$ & \\
\hline Cardiovascular events & 32 & 10.1 & 22 & 17.2 & 10 & 5.3 & $<0.001$ \\
\hline Non-fatal CV events & 30 & 9.4 & 20 & 15.6 & 10 & 5.3 & 0.002 \\
\hline Fatal CV events & 2 & 0.6 & 2 & 1.6 & 0 & 0.0 & NS \\
\hline Total mortality & 13 & 4.1 & 9 & 7.0 & 4 & 2.1 & 0.03 \\
\hline
\end{tabular}

In our study $64 \%$ of men and $62 \%$ of women were overweight and $24 \%$ of men and women were obese. This is much more than in a similar study in The Netherlands, where only $42 \%$ of men and $30 \%$ of women were overweight and $9 \%$ of men and $12 \%$ of women were obese (22). This difference may find its origin in the higher age of the patients in our study. However, the body weight only increased significantly with age in men. A Belgian study with a younger population between 35 and 49 years showed an overweight among $49 \%$ of men and $28 \%$ of women and obesity among $14 \%$ of men and $13 \%$ of women (23).

The treatment of overweight and obesity is important in view of a general management of CVR factors. A substantial decrease of the body weight is related to reduction of SBP by $20 \mathrm{mmHg}$, HbAlc by $15 \%$, TC by $10 \%$, LDL-C by $15 \%$, TG by $30 \%$ and increase of HDL-C by $8 \%$ (24). During the first part of the study all overweight and obese patients received individually designed dietary advice. Such dietary advice was also provided during the further follow up as part of the usual care. Unfortunately, these dietary advices were not recorded in the context of the present study.

Abdominal circumference increased significantly among men as well as women. Abdominal fat deposition results in an increased incidence of diabetes and cardiovascular disease. Body weight reduction is advised for all men with an abdominal circumfer- ence of $102 \mathrm{~cm}$ or more and for all women with an abdominal circumference of $88 \mathrm{~cm}$ or more (24).

\section{Cardiovascular Risk-assessment}

Our study showed a significant shift of patients from the group with the lowest CVR to the groups with moderate and high risk. This shift can at least be partly explained by ageing of participants, leading to an age related increase in tendency of blood pressure, lipid concentrations, and blood sugar (25).

In a Swedish study, a similar shift between risk groups was observed (8), which was related to age, but also to increased bodyweight and insufficient compliance to preventive measures. Insufficient compliance can also be suspected from our study because despite the intervention in 2002-2003 only few participants reached the target levels.

However, some studies reported even higher CV risks than in our Belgian population. A French study, for example, categorized $41 \%$ of the population in the high risk group, $46 \%$ in the moderate risk group and only $13 \%$ in the low risk group (20).

A similar study in The Netherlands showed that participants with an initial low CVR maintained their low risk during followup (12). As in our study the proportion of participants at low CVR decreased with time, yet this finding was not confirmed. 


\section{Treatment of Risk Factors}

High proportions of participants with CVR factors did not receive an intervention or treatment for these risk factors after the initial registration in 2002-2003. This was the case for $42 \%$ of participants with increased TC, despite the fact that diet and physical exercise have proven to be efficacious in decreasing TC levels $(2,7,26)$.

For LDL-C the situation was even worse: $47 \%$ of the participants with an increased LDL-C did not receive an intervention, although a review showed that an intensive and accurate treatment of LDL-C leads to a decrease of cardiovascular events (27).

Furthermore, 39\% of participants with decreased HDL-C and $20 \%$ of participants with increased TG did not receive an intervention.

It is not surprising that these low proportions of treated participants, often with a high CVR, lead to low proportions of participants attaining the treatment target levels. An American study confirms that only few of those at high CVR attain the target levels (28). It should be emphasized that target levels for patients at high CVR are stricter than for those at low CVR.

It has been proven that with an adequate anti-hypertensive treatment $90 \%$ of patients with high diastolic blood pressure can reach the $90 \mathrm{mmHg}$ target (29). But no less than one third of our study participants with hypertension did not receive any intervention at all. An explanation could be found in the fact that family physicians often use higher treatment and target levels than those indicated in the guidelines, as was shown by an American study (30). An Australian study, with a similar study population as in our study, also found that one third of the participants had hypertension and that only half of these patients were treated (31).

Our findings about the prevalence of diabetes and impaired glucose tolerance (IGT) are in line with other European studies. In a Swedish study $26 \%$ of men and $23 \%$ of women had an IGT (32). In the 45-64 years-old population in Finland, 10\% of men and $7 \%$ of women had diabetes (33).

\section{Morbidity and Mortality}

Our study showed more cardiovascular events and higher total mortality among men than among women. Men underwent more coronary artery procedures and had more myocardial infarctions. Also, we recorded more newly diagnosed COPD and gout in men than in women. However, it was not the aim of our study to detect correlations between CVR factors and mortality as it probably had insufficient power to detect these eventual correlations.

\section{Future Research}

The study is representative for a population that attended their family physician for a cardiovascular check-up. It is not excluded that this population is more interested in a healthy life style or is more afraid of a cardiovascular event.

Therefore future research should be population based. However, the results of the present study are useful as they are representative for the population seen in family practice. The results of the present study should be compared to a control group that didn't benefit from a brief cardiovascular intervention. Unfortunately, this comparison was not possible with this study design.

\section{CONCLUSIONS}

Seven years after a brief intervention in a cardiovascular prevention campaign, a significant increase of the abdominal circumference, serum triglycerides and fasting glycaemia of the participants was observed. In line with the initial aim of the cardiovascular prevention campaign a decrease of LDL-C was observed. However, very few participants attained the set target levels for the different CVR factors. This resulted in increased proportions of participants in the groups with high and moderate CVR. Most of the changes are probably attributable to age. The treatment of these patients is still not optimal and could be intensified.

\section{Acknowledgement}

The authors thank all participating family physicians from Overijse, Hoeilaart, Merchtem, Huldenberg and Oud-Heverlee.

\section{Sponsoring}

The local authorities of Overijse, Hoeilaart, Merchtem, Huldenberg and Oud-Heverlee gave logistic support in 2002-2003 as well as Bristol-Myers Squibb Pharmaceuticals who printed the questionnaires in 2002-2003.

\section{REFERENCES}

1. Lloyd-Williams F, O'Flaherty M, Mwatsama M, Birt C, Ireland R, Capewell S. Estimating the cardiovascular mortality burden attributable to the European Common Agricultural Policy on dietary saturated fats. Bull World Health Organ [Internet]. 2008 [cited 2010 May 15];86(7). Available from: http://www.who.int/bulletin/volumes/86/7/08-053728/ en/index.html.

2. Graham I, Atar D, Borch-Johnsen K, Boysen G, Burell G, Cifkova R, et al.; European Society of Cardiology (ESC) Committee for Practice Guidelines (CPG). European guidelines on cardiovascular disease prevention in clinical practice: executive summary: Fourth Joint Task Force of the European Society of Cardiology and Other Societies on Cardiovascular Disease Prevention in Clinical Practice (Constituted by representatives of nine societies and by invited experts). Eur Heart J. 2007 Oct;28(19):2375414.

3. Khan NA, Hemmelgarn B, Herman RJ, Bell CM, Mahon JL, Leiter LA, et al.; Canadian Hypertension Education Program. The 2009 Canadian Hypertension Education Program recommendations for the management of hypertension: Part 2-therapy. Can J Cardiol. 2009 May;25(5):287-98.

4. Kostis JB. The importance of managing hypertension and dyslipidemia to decrease cardiovascular disease. Cardiovasc Drugs Ther. 2007 Aug;21(4):297-309.

5. Roccatagliata D, Avanzini F, Monesi L, Caimi V, Lauri D, Longoni P, et al.; Collaborative Group Risk and Prevention Study. Is global cardiovascular risk considered in current practice? Treatment and control of hypertension, hyperlipidemia, and diabetes according to patients' risk level. Vasc Health Risk Manag. 2006;2(4):507-14.

6. Kotseva K, Wood D, De Backer G, De Bacquer D, Pyörälä K, Keil U; EUROASPIRE Study Group. EUROASPIRE III: a survey on the lifestyle, risk factors and use of cardioprotective drug therapies in coronary patients from 22 European countries. Eur J Cardiovasc Prev Rehabil. 2009 Apr;16(2):121-37.

7. Boland B, Christiaens T, Goderis G, Govaerts F, Philips H, Smeets F, et al. Global cardiovascular risk. Huisarts Nu. 2007;36(7):339-69. (In Dutch.)

8. Dahlöf B. Cardiovascular disease risk factors: epidemiology and risk assessment. Am J Cardiol. 2010 Jan 4;105(1 Suppl):3A-9A.

9. Wood D; Joint European Societies Task Force. Established and emerging cardiovascular risk factors. Am Heart J. 2001 Feb;141(2 Suppl):S49-57.

10. Devroey D, Kartounian J, Vandevoorde J, Betz W, Cogge M, De Man B, et al. Primary prevention of coronary heart disease in general practice: a cross sectional population study. Int J Clin Pract. 2004 Feb;58(2):130-8.

11. Engberg M, Christensen B, Karlsmose B, Lous J, Lauritzen T. General health screenings to improve cardiovascular risk profiles: a randomized 
controlled trial in general practice with 5-year follow-up. J Fam Pract. 2002 Jun;51(6):546-52.

12. van Weel C, Bakx C, van den Hoogen H, Thien T, van den Bosch W. Longterm outcome of cardiovascular prevention: a Nijmegen Academic Family Practices Network study. J Am Board Fam Med. 2006 Jan-Feb;19(1):62-8.

13. Friedewald WT, Levy RI, Fredrickson DS. Estimation of the concentration of low-density lipoprotein cholesterol in plasma, without use of the preparative ultracentrifuge. Clin Chem. 1972 Jun;18(6):499-502.

14. De Cort P, Christiaens T, Philips H, Goossens M, Van Royen P. Hypertension. Huisarts Nu. 2009;38(9):340-61. (In Dutch.)

15. Wens J, Sunaert P, Nobels F, Feyen L, Van Crombrugge P, Bastiaens H, et al. Diabetes mellitus type 2. Huisarts Nu. 2005;34(2):1-52.

16. Graham I, Atar D, Borch-Johnsen K, Boysen G, Burell G, Cifkova R, et al.; Fourth Joint Task Force of the European Society of Cardiology and other societies on cardiovascular disease prevention in clinical practice (constituted by representatives of nine societies and by invited experts). European guidelines on cardiovascular disease prevention in clinical practice: full text. Eur J Cardiovasc Prev Rehabil. 2007 Sep;14 Suppl 2:S1-113.

17. World Health Organization. Prevention of cardiovascular disease: pocket guidelines for assessment and management of cardiovascular risk. Geneva: WHO; 2007.

18. Conroy RM, Pyörälä K, Fitzgerald AP, Sans S, Menotti A, De Backer $\mathrm{G}$, et al.; SCORE project group. Estimation of ten-year risk of fatal cardiovascular disease in Europe: the SCORE project. Eur Heart J. 2003 Jun;24(11):987-1003.

19. Rasbash J, Steele F, Browne WJ, Goldstein H. A user's guide to MlwiN: version 2.10. Bristol: Centre for Multilevel Modelling, University of Bristol; 2009.

20. Cacoub P, Tocque-Le Gousse E, Fabry C, Hermant S, Petzold L. Application in general practice of treatment guidelines for patients with dyslipidaemia: the RESPECT study. Arch Cardiovasc Dis. 2008 NovDec;101(11-12):715-21.

21. Carroll MD, Lacher DA, Sorlie PD, Cleeman JI, Gordon DJ, Wolz M, et al. Trends in serum lipids and lipoproteins of adults, 1960-2002. JAMA. 2005 Oct 12;294(14):1773-81.

22. van Dijk L, Otters HB, Schuit AJ. Moderately overweight and obese patients in general practice: a population based survey. BMC Fam Pract. 2006 Jul 7;7:43.

23. Moreau M, Valente F, Mak R, Pelfrene E, de Smet P, De Backer G, et al. Obesity, body fat distribution and incidence of sick leave in the Belgian workforce: the Belstress study. Int J Obes Relat Metab Disord. 2004 Apr;28(4):574-82.

24. Van Royen P, Bastiaens H, D'Hondt A, Provoost C, Van den Borght W. Overweight and obesity in adults in primary care. Huisarts $\mathrm{Nu}$. 2006;35(3):118-40. (In Dutch.)

25. Tuomilehto J. Impact of age on cardiovascular risk: implications for cardiovascular disease management. Atheroscler Suppl. 2004 May;5(2):9-17.

26. National Institute for Health and clinical excellence (NHC). Lipid modification: cardiovascular risk assessment and the modification of blood lipids for the primary and secondary prevention of cardiovascular disease [Internet]. London: NHC; 2008 [cited 2010 Apr 25]. Available from: http://www.nice.org.uk/nicemedia/pdf/CG67NICEguideline.pdf.

27. Kostis JB. The importance of managing hypertension and dyslipidemia to decrease cardiovascular disease. Cardiovasc Drugs Ther. 2007 Aug;21(4):297-309.

28. Ghandehari H, Kamal-Bahl S, Wong ND. Prevalence and extent of dyslipidemia and recommended lipid levels in US adults with and without cardiovascular comorbidities: the National Health and Nutrition Examination Survey 2003-2004. Am Heart J. 2008 Jul;156(1):112-9.

29. Black HR. Optimal blood pressure: how low should we go? Am J Hypertens. 1999 Nov;12(11 Pt 2):113S-20S.

30. Hyman DJ, Pavlik VN. Self-reported hypertension treatment practices among primary care physicians: blood pressure thresholds, drug choices, and the role of guidelines and evidence-based medicine. Arch Intern Med. 2000 Aug 14-28;160(15):2281-6.

31. Janus ED, Bunker SJ, Kilkkinen A, Mc Namara K, Philpot B, Tideman $\mathrm{P}$, et al. Prevalence, detection and drug treatment of hypertension in a rural Australian population: the Greater Green Triangle risk factor study 2004-2006. Intern Med J. 2008 Dec;38(12):879-86.

32. Alvarsson M, Hilding A, Ostenson CG. Factors determining normalization of glucose intolerance in middle-aged Swedish men and women: a 8-10-year follow-up. Diabet Med. 2009 Apr;26(4):345-53.

33. Ylihärsilä H, Lindström J, Eriksson JG, Jousilahti P, Valle TT, Sundvall $\mathrm{J}$, et al. Prevalence of diabetes and impaired glucose regulation in 45- to 64-year-old individuals in three areas of Finland. Diabet Med. 2005 Jan;22(1):88-91 